NASA Technical Memorandum 107473

AIAA-97-2913

\title{
Comparison of High Aspect Ratio Cooling Channel Designs for a Rocket Combustion Chamber
}

Mary F. Wadel

Lewis Research Center

Cleveland, Ohio

Prepared for the

33rd Joint Propulsion Conference and Exhibit cosponsored by AIAA, ASME, SAE, and ASEE Seattle, Washington, July 6-9, 1997

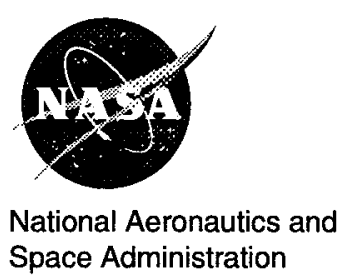




\title{
COMPARISON OF HIGH ASPECT RATIO COOLING CHANNEL DESIGNS FOR A ROCKET COMBUSTION CHAMBER
}

\author{
Mary F. Wadel \\ National Aeronautics and Space Administration \\ Lewis Research Center \\ Cleveland, Ohio 44135
}

\begin{abstract}
$\underline{\text { Abstract }}$
An analytical investigation on the effect of high aspect ratio (height/width) cooling channels in a liquid hydrogen cooled rocket combustion chamber was performed. Different coolant channel designs were evaluated for their effect on hot-gas-side wall temperature and coolant pressure drop. Coolant channel design elements considered were length of combustion chamber in which high aspect ratio cooling was applied, number of coolant channels, and coolant channel shape. Seven coolant channel designs were investigated using a coupling of the Rocket Thermal Evaluation code and the TwoDimensional Kinetics code. Initially, each coolant channel design was developed, without consideration for fabrication, to reduce the hot-gas-side wall temperature from a given conventional cooling channel baseline. These designs produced hot-gas-side wall temperature reductions up to 22 percent, with coolant pressure drop increases as low as 7.5 percent from the baseline. Fabrication constraints for milled channels were applied to the seven designs. These produced hot-gas-side wall temperature reductions of up to 20 percent, with coolant pressure drop increases as low as 2 percent. Using high aspect ratio cooling channels for the entire length of the combustion chamber had no additional benefit on hot-gas-side wall temperature over using high aspect ratio cooling channels only in the throat region, but increased coolant pressure drop 33 percent. Independent of coolant channel shape, high aspect ratio cooling was able to reduce the hotgas-side wall temperature by at least 8 percent, with as low as a 2 percent increase in coolant pressure drop. The design with the highest overall benefit to hot-gas-side wall temperature and minimal coolant pressure drop increase was the design which used bifurcated cooling channels and high aspect ratio cooling in the throat region.
\end{abstract}

Introduction

Among the many engineering challenges of reusable rocket engines is the need for chamber liners which will withstand the harsh combustion environment for many thermal cycles before failure. This is generally accomplished with a regenerative cooling system. In order to maintain chamber life, the cooling must keep the hot-gasside wall temperature $\left(\mathrm{T}_{\mathrm{gw}}\right)$ well below the material's melting limit. One solution to this problem is the use of high aspect ratio (height/width) cooling channels (HARCC).

Subscale and validation experiments at NASA Lewis Research Center have shown HARCC to significantly reduce the $T_{g w}$ for the same pressure drop or with a modest pressure drop increase. ${ }^{1,2}$ These tests also showed that HARCC and a decreased coolant mass flow rate could reduce the coolant pressure drop and still achieve a modest reduction in the $\mathrm{T}_{\mathrm{gw}}$. These experiments were conducted with bifurcated coolant channels, which had a high aspect ratio in the throat region.

HARCC has been experimentally investigated, but past analytical study has been limited. Previously, computer capabilities limited analytical study due to the need for super computing capability and large computing times. Advances in computer technology now make codes able to run in much shorter times using workstations. Investigation into the appropriate way to apply high aspect ratio cooling can now be done in relatively short periods of time with multiple iterations.

This study investigated the affect of HARCC, considering different coolant channel designs, on $\mathrm{T}_{\mathrm{gw}}$ and coolant channel pressure drop for a liquid hydrogen $\left(\mathrm{LH}_{2}\right)$

"Copyright $\bigcirc$ by the American Institute of Aeronautics and Astronautics, Inc. No copyright is asserted in the United States under Title 17, U.S. Code. The U.S. Government has a royalty-free license to exercise all rights under the copyright claimed herein for Governmental Purposes. All other rights are reserved by the copyright owner." 
cooled rocket combustion chamber. The $\mathrm{LH}_{2}$ coolant mass flow rate was held constant for the entire study. Seven coolant channel designs were developed which varied the elements of; the chamber length in which HARCC was applied, the number of coolant channels, and coolant channel shape. For this study, each of the seven coolant channel designs was initially developed, without consideration for fabrication, to reduce the maximum $\mathrm{T}_{\mathrm{gw}}$ to $667 \mathrm{~K}\left(1200^{\circ} \mathrm{R}\right)$ from a given conventional cooling channel baseline temperature profile with a maximum $\mathrm{T}_{\mathrm{gw}}$ of $778 \mathrm{~K}\left(1400^{\circ} \mathrm{R}\right)$. After these designs were determined, the seven coolant channel designs were modified to reflect current fabrication techniques. The seven designs were then evaluated to obtain an overall design, which had the most benefit to $\mathrm{T}_{\mathrm{gw}}$ without significant adverse impact on coolant pressure drop.

\section{Combustion Chamber Design}

In order to make a comparison of the different HARCC designs, the thrust chamber contour selected, shown in Fig. 1, was the one used for the previous HARCC validation experiments. ${ }^{2,3}$ This contour was based on a $89 \mathrm{kN}$ $\left(20000 \mathrm{lb}_{\mathrm{f}}\right.$ ) thrust chamber previously tested at NASA Lewis Research Center for thermal fatigue and validation studies. The combustion chamber used an oxygen free electrical (OFE) copper inner liner with a nickel closeout structural jacket. The injector had 91 liquid oxygen (LOX) posts, and all fuel flowed through a porous-sintered-wire mesh face plate.

The combustion chamber pressure used was $11 \mathrm{MPa}$ (1600 psia) with a mixture ratio (oxygen/fuel) of 6.0. A rocket combustion analysis code (ROCCID) was used to obtain an axial profile of the mixture ratio in the combustion chamber upstream of the throat. ${ }^{4}$ LOX and gaseous hydrogen $\left(\mathrm{GH}_{2}\right)$ were used as propellants, with $\mathrm{LH}_{2}$ as the coolant. The LOX mass flow rate used was $13.8 \mathrm{~kg} / \mathrm{sec}$ $\left(30.4 \mathrm{lb}_{\mathrm{m}} / \mathrm{sec}\right)$, and the $\mathrm{GH}_{2}$ and $\mathrm{LH}_{2}$ mass flow rates used were $2.3 \mathrm{~kg} / \mathrm{sec}\left(5.1 \mathrm{lb}_{\mathrm{m}} / \mathrm{sec}\right)$ each. The propellant and coolant inlet temperatures were assumed to be $91.7 \mathrm{~K}$ $\left(165^{\circ} \mathrm{R}\right)$ for $\mathrm{LOX}, 300 \mathrm{~K}\left(540^{\circ} \mathrm{R}\right)$ for $\mathrm{GH}_{2}$, and $44.4 \mathrm{~K}$ $\left(80.0^{\circ} \mathrm{R}\right)$ for $\mathrm{LH}_{2}$. For this study, the $\mathrm{LH}_{2}$ coolant mass flow rate was held constant.

\section{Coolant Channel Design}

\section{Conventional Baseline Channel Design}

In order to design the HARCC chambers to reduce $\mathrm{T}_{\mathrm{gw}}$, a baseline design with conventional coolant channels was used. This baseline design uses 100 coolant channels at a conventional aspect ratio of 2.5. It has the same chamber contour and conditions as assumed for the HARCC designs. In an effort to make a comparison with the baseline, the total coolant channel area at a given axial location of the combustion chamber was kept the same between the baseline and the different designs.

\section{Coolant Channel Designs}

The three coolant channel design criteria considered were; the length of chamber in which HARCC was applied, the number of coolant channels, and coolant channel shape. Table I presents the seven different design combinations investigated.

TABLE I.-MATRIX OF BASIC COOLANT CHANNEL DESIGNS

\begin{tabular}{|c|c|c|c|c|}
\hline \multirow{2}{*}{$\begin{array}{l}\text { Channel } \\
\text { shape }\end{array}$} & \multicolumn{3}{|c|}{ Number of coolant channels } & \multirow{2}{*}{$\begin{array}{l}\text { Design } \\
\text { number }\end{array}$} \\
\hline & $\begin{array}{l}\text { Chamber } \\
\text { region }\end{array}$ & $\begin{array}{l}\text { Throat } \\
\text { region }\end{array}$ & $\begin{array}{l}\text { Nozzle } \\
\text { region }\end{array}$ & \\
\hline \multirow[t]{4}{*}{ Continuous } & 100 & 103 & 100 & 1 \\
\hline & 300 & 203 & 263 & 2 \\
\hline & 100 & 18 & 100 & 3 \\
\hline & 200 & $3 \times 3$ & 200 & 4 \\
\hline Bifurcated & 100 & 203 & 100 & 5 \\
\hline \multirow[t]{2}{*}{ Stepped } & 100 & 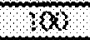 & 100 & 6 \\
\hline & 200 & 200 & 200 & 7 \\
\hline
\end{tabular}

${ }^{\mathrm{a}}$ Shaded regions indicate areas of HARCC.

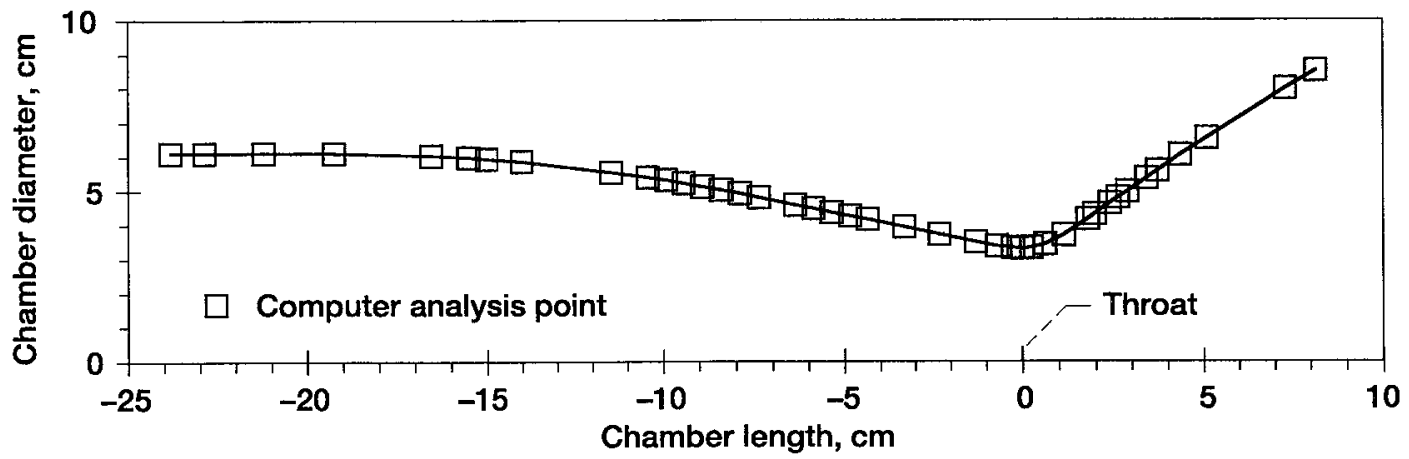

Figure 1.-Combustion chamber contour with RTE and TDK computer analysis points indicated. 
Top views

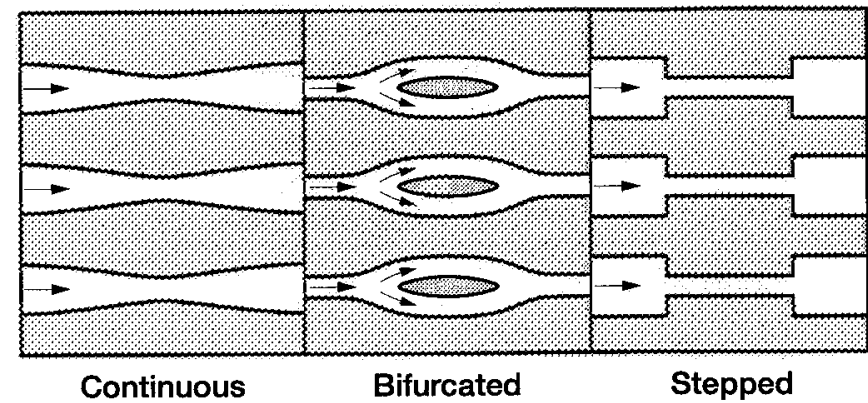

Cross-sectional view

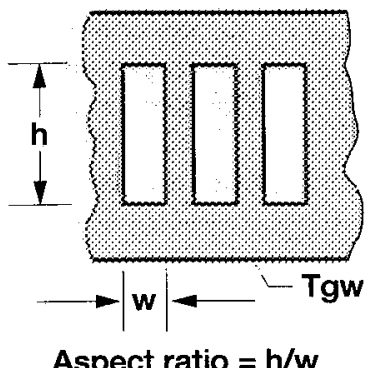

Figure 2.-Schematics of different coolant channel shapes evaluated.

\section{Coolant Channel Shape}

The different coolant channel shapes considered were continuous, bifurcated, and stepped. Schematics for the different shapes are shown in Fig. 2. All of the coolant channels were rectangular. Continuous channels were channels which had smooth transitions in width. Bifurcated channels were channels which were split into two channels and combined back to a single channel. Stepped channels were channels which made a sharp geometry change to another width.

\section{Computer Codes}

The designs were evaluated for their $\mathrm{T}_{\mathrm{gw}}$ and coolant pressure drop using an iterative coupling between two different computer codes. The codes were a three dimensional rocket thermal evaluation code (RTE) and a nozzle analysis code, TDK, which uses an inviscid boundary layer analysis technique.,6 RTE and TDK were coupled by iterating between heat transfer rate and $\mathrm{T}_{\mathrm{gw}}$.

This method of predicting the $\mathrm{T}_{\mathrm{gw}}$ and coolant channel pressure drop has been compared against experimental results obtained during HARCC validation tests. ${ }^{2}$ The method was able to predict experimental coolant rib thermocouple temperatures within an average of 9 percent and experimental coolant pressure drops within an average of 25 percent. Although the coolant pressure drop predictions were not as accurate as the temperature predictions, the RTE code was run assuming smooth channels. However, the actual combustion chamber channels did not have perfectly smooth channels in the bifurcation regions, and possible burrs existed in the coolant entry and exit manifolds, after welding. Each of these were localized to particular channels or nonuniform in a circumferential region of the chamber. These manufacturing consequences could account for the discrepancy in the code predictions and data, and are very difficult to predict and model due to the nonuniformity. For this study, smooth coolant channels were assumed in order to make a comparison between each coolant channel design. Although the assumption of smooth coolant channels would not give the most accurate assessment of coolant pressure drop, it would eliminate error for assumptions in localized manufacturing consequences.

\section{Coolant Channel Design Method}

The coolant channel design method used RTE and TDK coupled to evaluate $\mathrm{T}_{\mathrm{gw}}$ and coolant pressure drop. Using the $\mathrm{T}_{\mathrm{gw}}$ and coolant pressure drop, a coolant channel design was formulated which would reduce the $\mathrm{T}_{\mathrm{gw}}$ in the hot throat region from the baseline. Figure 3 shows a schematic of a conventionally cooled $\mathrm{T}_{\mathrm{gw}}$ profile and a target $T_{\mathrm{gw}}$ profile using HARCC. A reduction of the $T_{\mathrm{gw}}$ in the throat region from $778 \mathrm{~K}\left(1400^{\circ} \mathrm{R}\right)$ to below $667 \mathrm{~K}$ $\left(1200^{\circ} \mathrm{R}\right)$ was used as the target HARCC profile. The $\mathrm{T}_{\mathrm{gw}}$ limit of $667 \mathrm{~K}\left(1200^{\circ} \mathrm{R}\right)$ was chosen based upon an experimental study of the fatigue life of OFE copper thrust chambers. ${ }^{7}$ This study showed that a reduction of the $T_{\mathrm{gw}}$ from $778 \mathrm{~K}\left(1400^{\circ} \mathrm{R}\right)$ to $667 \mathrm{~K}\left(1200^{\circ} \mathrm{R}\right)$ could more than double the number of thermal cycles before failure. The axial locations evaluated along the combustion chamber contour are indicated in Fig. 1. The flow chart given in Fig. 4 represents the method used to develop the coolant

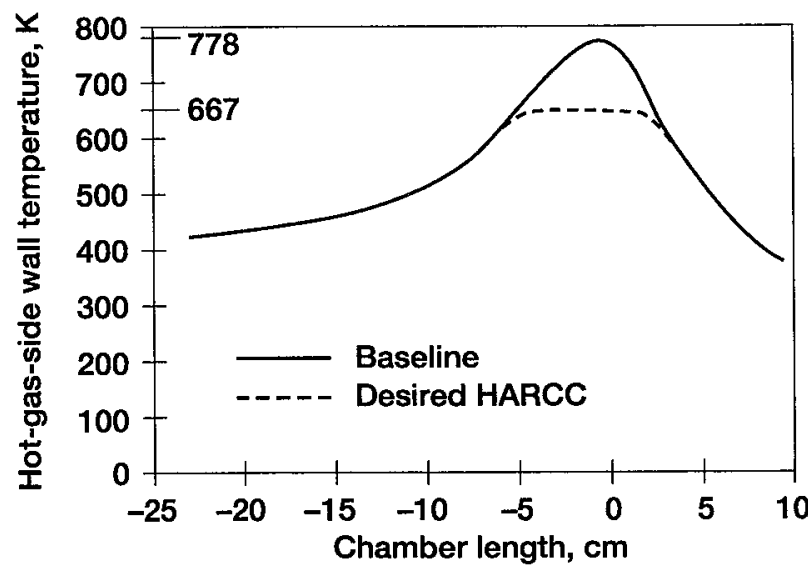

Figure 3.-Schematic of desired hot-gas-side wall temperature using high aspect ratio cooling. 


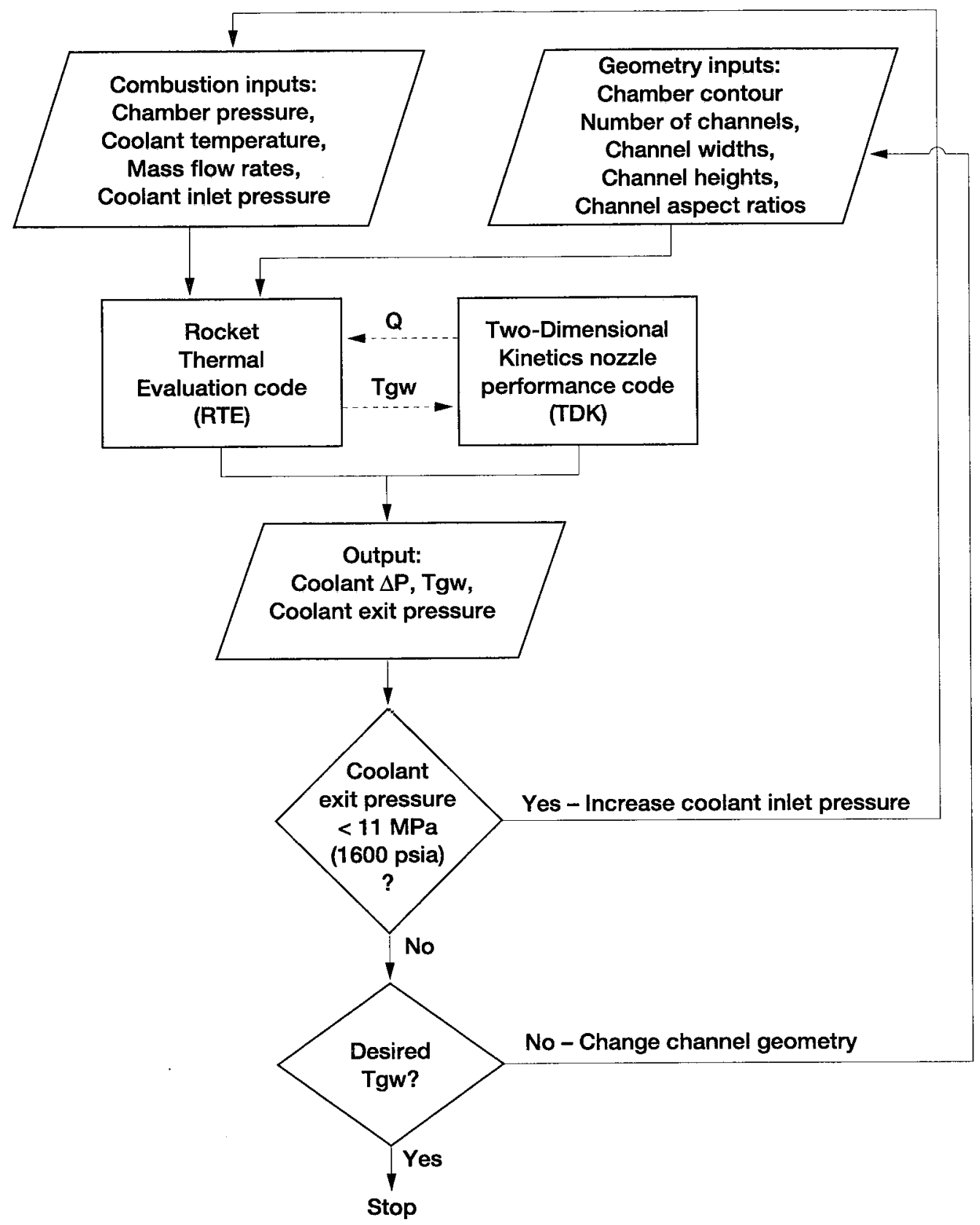

Figure 4.-Flow chart of computer design and analysis method.

channel designs to obtain $T_{g w}$ profiles for each design which would most closely match the target HARCC profile shown in Fig. 3.

As shown in Fig. 4, the coolant inlet pressure was increased until the coolant exit pressure was above the chamber pressure. This was done to simulate the positive pressure differential needed during actual combustion in order to prevent back flow into the coolant channels in the case of a failure. Once the coolant pressure was corrected, the coolant channel geometry was modified based upon the resultant $\mathrm{T}_{\mathrm{gw}}$.
Fabrication Criteria

When fabrication was taken into consideration, it was limited to current milling capabilities. The most important of these are:

- Aspect ratios $\leq 8$

- Coolant channel heights $\leq 0.51 \mathrm{~cm}(0.20 \mathrm{in}$.)

- Coolant channel widths $\geq 0.051 \mathrm{~cm}(0.02 \mathrm{in}$.)

- Coolant channel landwidths $\geq 0.051 \mathrm{~cm}(0.02$ in.)

- No sharp changes in coolant channel width or height (except the width changes for the stepped channel design) 


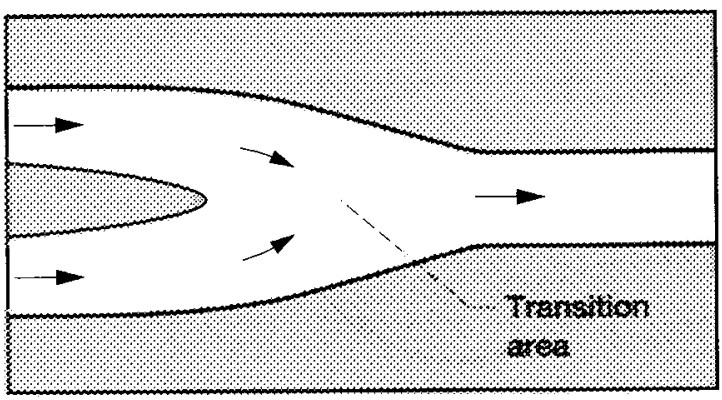

Figure 5.-Schematic of bifurcation fabrication.

The bifurcated channels had an additional fabrication consideration. With current milling techniques, it is very difficult to perfectly bifurcate a channel. Usually there is a transition section created during milling. This transition is depicted in Fig. 5. The result is an exaggerated increase in flow area of the single coolant channel, which reduces the heat transfer capabilities at that point, and can lead to a local increase in $\mathrm{T}_{\mathrm{gw}}$. This transition was taken into account for the bifurcated channel design. The total coolant flow area for each axial location at these bifurcation transition points was greater than the baseline design. This allowed for a more accurate assessment of the affect the transition area had on the $\mathrm{T}_{\mathrm{gw}}$ for the bifurcation design.

\section{$\underline{\text { Results and Discussion }}$}

Using the design and analysis methodology described, the final coolant channel designs, corresponding $\mathrm{T}_{\mathrm{gw}} \mathrm{s}$ and coolant channel pressure drops were determined and compared. Each design given in Table I was evaluated with and without consideration for fabrication.

\section{Coolant Channel Designs Without Consideration for Fabrication}

The coolant channel designs were first determined without consideration for fabrication. $\mathrm{T}_{\mathrm{gw}} \mathrm{s}$ and coolant channel pressure drops were determined with the resultant geometries.

Each design attempted to reproduce the target HARCC $\mathrm{T}_{\mathrm{gw}}$ profile given in Fig. 3. Figures 6 to 12 show each design's actual $\mathrm{T}_{\mathrm{gw}}$ compared with the baseline $\mathrm{T}_{\mathrm{gw}}$. As shown in Figs. 6 to 12, each design resulted in $\mathrm{T}_{\mathrm{gw}}$ below the limit of $667 \mathrm{~K}\left(1200^{\circ} \mathrm{R}\right)$, with a temperature profile similar to the profile given in Fig. 3. Table II shows the highest $\mathrm{T}_{\mathrm{gw}}$ and the coolant pressure drop for each of the designs, without considering fabrication. As shown in Table II, $\mathrm{T}_{\mathrm{gW}}$ reductions from 16.5 to 22 percent were obtained. Figs. 7, 9, and 12, which correspond to designs 2,4 , and 7 , show the entire $T_{g w}$ profiles well below the baseline due to the use of 200 cooling channels throughout the entire chamber region. Figures 11 and 12, which

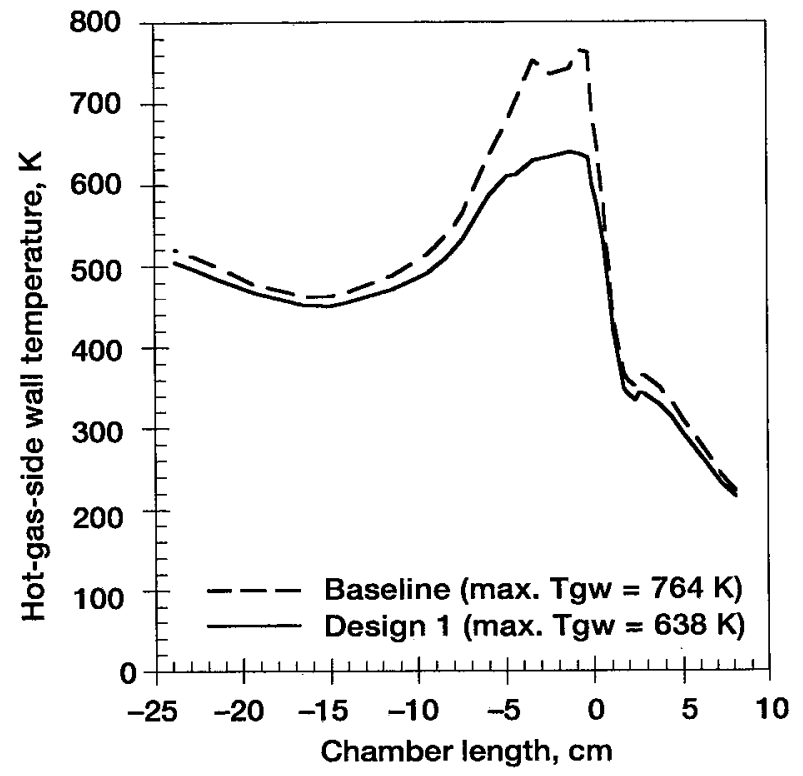

Figure 6.-Hot-gas-side wall temperature comparison of Design 1 and baseline, without consideration for fabrication.

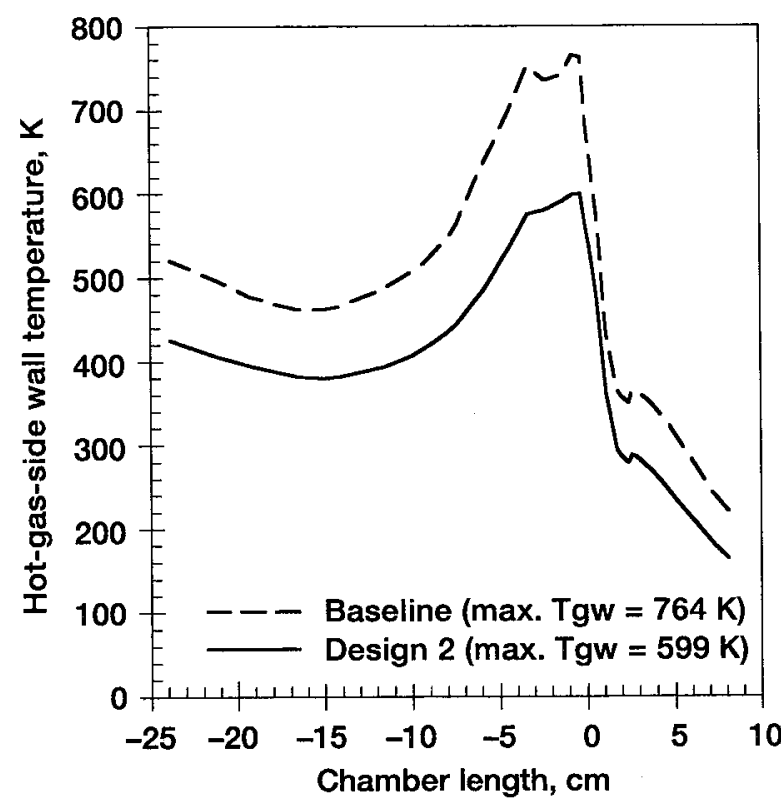

Figure 7.-Hot-gas-side wall temperature comparison of Design 2 and baseline, without consideration for fabrication. 


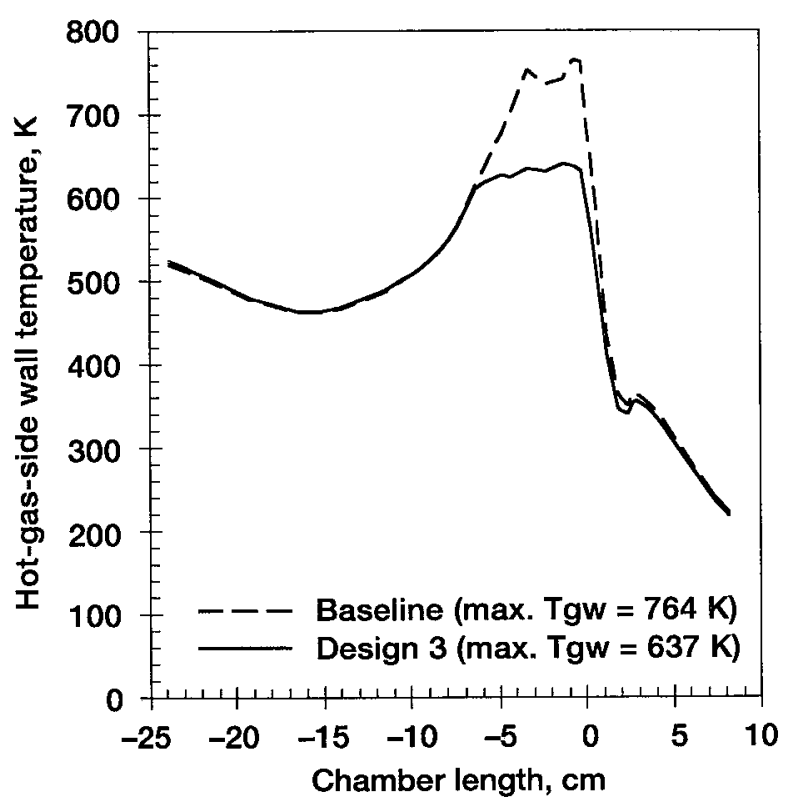

Figure 8.-Hot-gas-side wall temperature comparison of Design 3 and baseline, without consideration for fabrication.

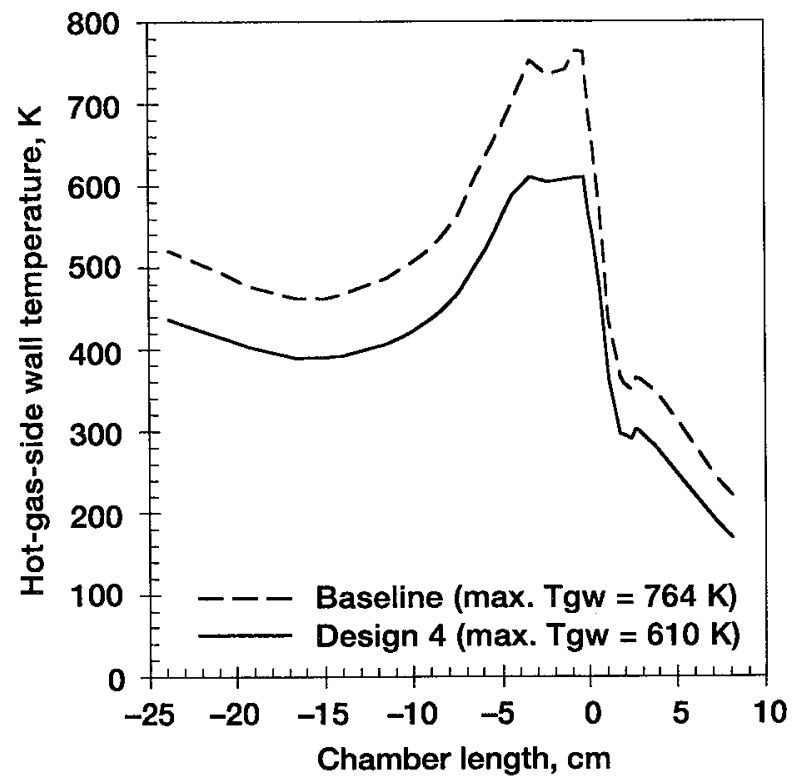

Figure 9.-Hot-gas-side wall temperature comparison of Design 4 and baseline, without consideration for fabrication.

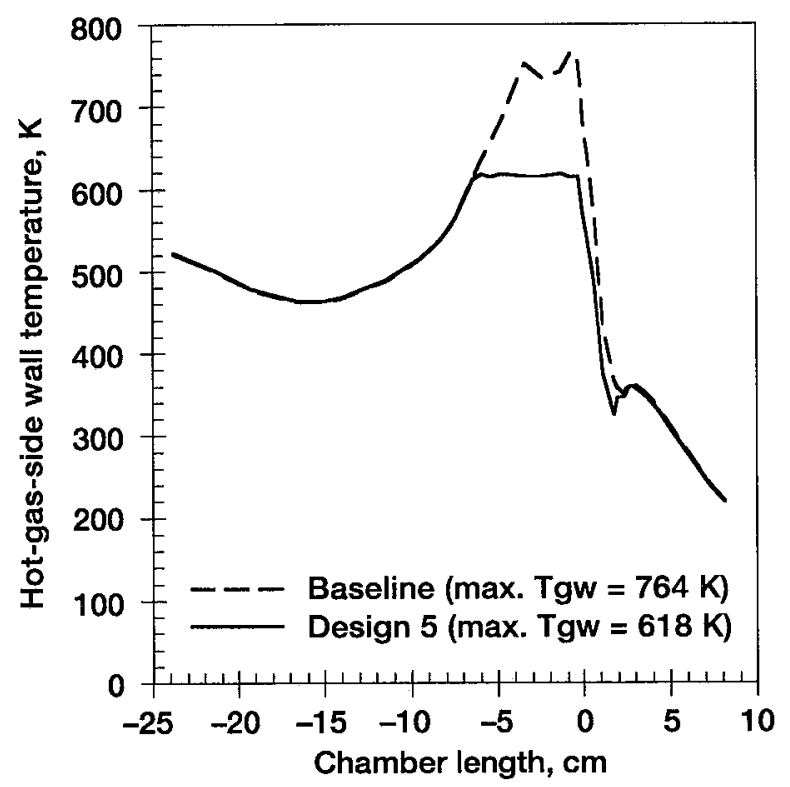

Figure 10.-Hot-gas-side wall temperature comparison of Design 5 and baseline, without consideration for fabrication.

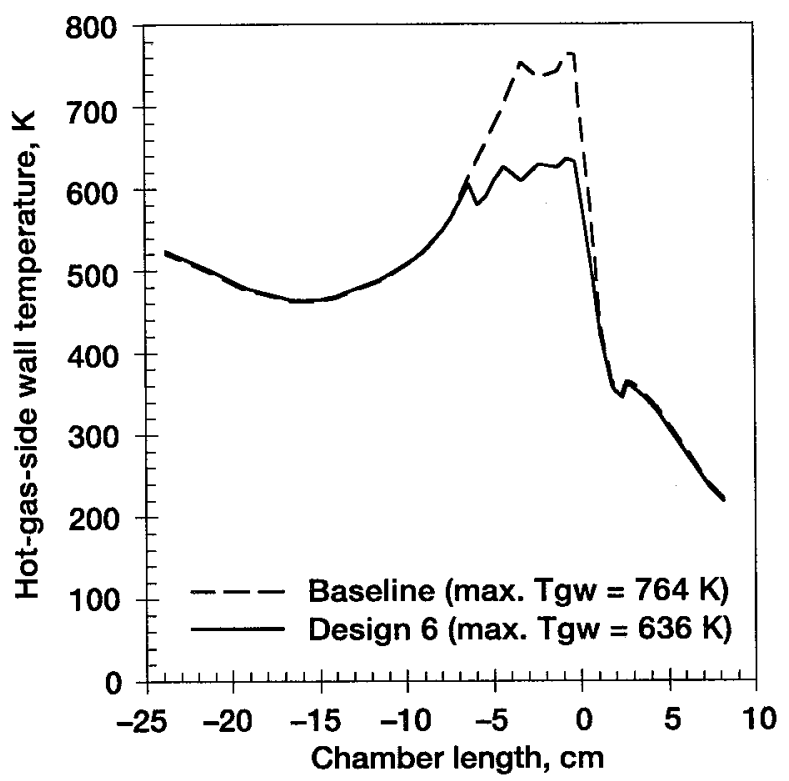

Figure 11.-Hot-gas-side wall temperature comparison of Design 6 and baseline, without consideration for fabrication. 


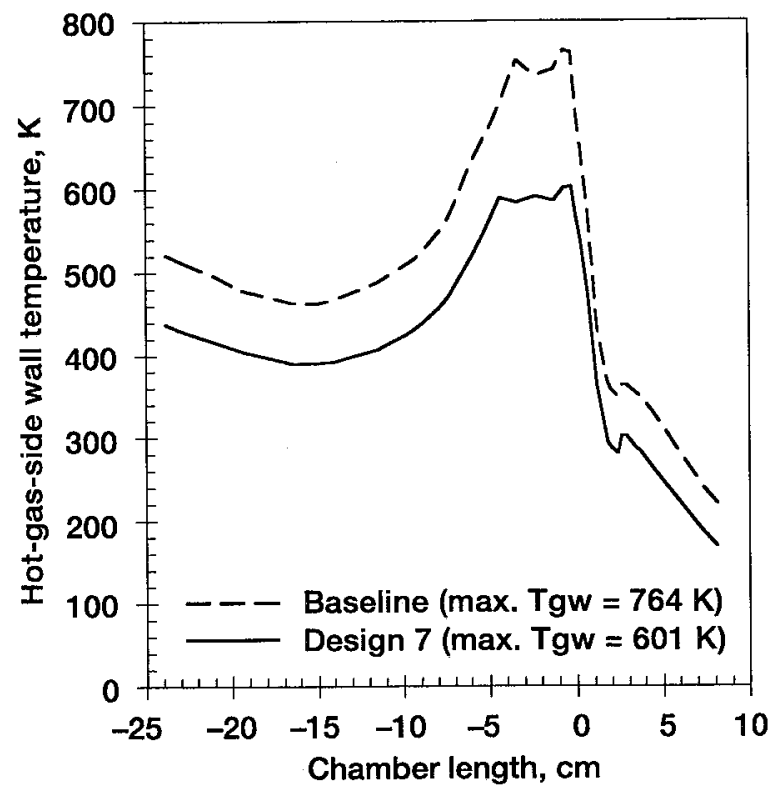

Figure 12.-Hot-gas-side wall temperature comparison of Design 7 and baseline, without consideration for fabrication.

TABLE II.-COMPARISON OF MAXIMUM PREDICTED HOT-GAS-WALL TEMPERATURES AND TOTAL COOLANT CHANNEL PRESSURE DROPS

\begin{tabular}{|c|c|c|c|c|}
\hline $\begin{array}{c}\text { Design } \\
\text { number }\end{array}$ & \multicolumn{2}{|c|}{$\begin{array}{c}\text { Without consideration } \\
\text { for f abrication }\end{array}$} & \multicolumn{2}{|c|}{ Considering fabrication } \\
\hline & $\begin{array}{c}\mathrm{T}_{\mathrm{gw}} \\
\mathrm{K}\left({ }^{\circ} \mathrm{R}\right)\end{array}$ & $\begin{array}{c}\Delta \mathrm{P} \\
\mathrm{MPa}(\mathrm{psi})\end{array}$ & $\begin{array}{c}\mathrm{T}_{\mathrm{gw}} \\
\mathrm{K}\left({ }^{\circ} \mathrm{R}\right)\end{array}$ & $\begin{array}{c}\Delta \mathrm{P} \\
\mathrm{MPa}(\mathrm{psi})\end{array}$ \\
\hline Baseline & $764(1376)$ & $3.7(540)$ & $764(1376)$ & $3.7(540)$ \\
\hline 1 & $638(1149)$ & $4.6(670)$ & $698(1257)$ & $4.1(600)$ \\
\hline 2 & $599(1079)$ & $5.0(720)$ & $608(1094)$ & $5.0(720)$ \\
\hline 3 & $637(1146)$ & $4.3(630)$ & $701(1262)$ & $3.9(570)$ \\
\hline 4 & $610(1098)$ & $4.6(660)$ & $609(1096)$ & $4.8(690)$ \\
\hline 5 & $618(1112)$ & $4.0(580)$ & $613(1103)$ & $4.07(590)$ \\
\hline 6 & $636(1144)$ & $4.4(640)$ & $702(1264)$ & $3.8(550)$ \\
\hline 7 & $601(1082)$ & $4.7(680)$ & $614(1106)$ & $4.6(670)$ \\
\hline
\end{tabular}

correspond to designs 6 and 7, do not have a smooth reduced $\mathrm{T}_{\mathrm{gw}}$, but rather show fluctuations in the temperature profile. This is due to the abrupt changes in the coolant channel width based upon the stepped coolant channel design configuration.

Coolant channel pressure drops were also calculated for each design. Each of the designs resulted in a higher coolant pressure drop than the baseline. These pressure drop increases ranged from 7.5 to 33 percent. As expected, the highest coolant pressure drop came from design 2 . This was due to using high aspect ratio cooling throughout the entire chamber, and using 200 cooling channels for the entire length of the chamber. The lowest coolant pressure drop increase ( 7.5 percent), came from design 5 , which used bifurcated coolant channels.

All of the designs were able to produce $\mathrm{T}_{\mathrm{gw}}$ profiles similar to the profile shown in Fig. 3. Table III shows the significant geometry requirements to obtain the reduced $\mathrm{T}_{\mathrm{gw}}$ s shown in Figs. 6 to 12 . As shown in Table III, designs 1,3 , and 6 have extremely high aspect ratio requirements of 40 , channel heights up to $1.02 \mathrm{~cm}$ (0.400 in.), and channel widths of $0.025 \mathrm{~cm}(0.010 \mathrm{in}$.). Designs $2,4,5$, and 7 have geometry requirements that are not as extreme as designs 1,3 , and 6 , and are closer to fabrication capabilities.

Once the coolant channel designs were determined, the seven designs were compared. The use of HARCC throughout the entire chamber length, designs 1 and 2, produced $\mathrm{T}_{\mathrm{gw}}$ profiles similar to the other designs. However, the coolant pressure drops incurred were 24 and 33 percent, respectively. The use of 200 channels through out the entire chamber, designs 2,4 , and 7, produced the highest benefit to the $\mathrm{T}_{\mathrm{gw}}$ with reductions of 20 to 22 percent, but incurred coolant pressure drops of 22 to 33 percent. All of the HARCC designs produced a reduction in $\mathrm{T}_{\mathrm{gw}}$ of at least 16.5 percent, with coolant channel pressure drop increases as low as 7.5 percent. Based upon the $\mathrm{T}_{\mathrm{gw}}$ and coolant channel pressure drop, design 5 resulted in the highest overall benefit. Although design 5 does not have the 22 percent reduction in $\mathrm{T}_{\mathrm{gw}}$ as design 2 ,

TABLE III-_GEOMETRY COMPARISONS OF DESIGNS WITHOUT CONSIDERATION FOR FABRICATION

\begin{tabular}{|c|c|c|c|c|}
\hline $\begin{array}{c}\text { Design } \\
\text { number }\end{array}$ & $\begin{array}{c}\text { Highest } \\
\text { aspect ratio }\end{array}$ & $\begin{array}{c}\text { Maximum channel } \\
\text { height, } \\
\text { cm (in) }\end{array}$ & $\begin{array}{c}\text { Minimum channel } \\
\text { width, } \\
\text { cm (in) }\end{array}$ & $\begin{array}{c}\text { Minimum } \\
\text { landwidth, } \\
\text { cm (in) }\end{array}$ \\
\hline 1 & 40.0 & $1.02(0.400)$ & $0.025(0.010)$ & $0.183(0.072)$ \\
\hline 2 & 6.2 & $0.318(0.125)$ & $0.046(0.018)$ & $0.056(0.022)$ \\
\hline 3 & 40.0 & $1.02(0.400)$ & $0.025(0.010)$ & $0.165(0.065)$ \\
\hline 4 & 5.0 & $0.254(0.100)$ & $0.051(0.020)$ & $0.043(0.017)$ \\
\hline 5 & 8.9 & $0.587(0.231)$ & $0.051(0.020)$ & $0.043(0.017)$ \\
\hline 6 & 40.0 & $1.02(0.400)$ & $0.025(0.010)$ & $0.135(0.053)$ \\
\hline 7 & 6.2 & $0.292(0.115)$ & $0.046(0.018)$ & $0.043(0.017)$ \\
\hline
\end{tabular}


it does have a 19 percent $T_{g w}$ reduction and the lowest coolant pressure drop increase of 7.5 percent.

\section{Coolant Channel Designs Considering Fabrication}

After the coolant channel designs had been determined to achieve the $\mathrm{T}_{\mathrm{gw}}$ profile shown in Fig. 3, the designs were modified for fabrication. $\mathrm{T}_{\mathrm{gw}} \mathrm{s}$ and coolant channel pressure drops for each design were then determined.

Each design was evaluated to obtain its $\mathrm{T}_{\mathrm{gw}}$ profile based upon fabrication constraints. Figures 13 to 19 show each design's $\mathrm{T}_{\mathrm{gw}}$ compared with the baseline $\mathrm{T}_{\mathrm{gw}}$ and the $\mathrm{T}_{\mathrm{gw}}$ achieved without considering fabrication. Figures 13, 15 , and 18 , which correspond to designs 1,3 , and 6 , show $\mathrm{T}_{\mathrm{gw}}$ profiles with only modest decreases in temperature once fabrication was taken into consideration. Table II shows the highest $T_{g w}$ and coolant pressure drop for each of the designs after considering fabrication. As shown in Table II, designs 1, 3, and 6 have temperature reductions of 8 percent. Figures 14, 16, and 19, which correspond to designs 2,4 , and 7 , show minimal change in the $\mathrm{T}_{\mathrm{gw}} \mathrm{s}$ once fabrication was considered. These designs retained the 20 percent reduction in $\mathrm{T}_{\mathrm{gw}}$, as shown in Table II. Design 5 resulted in the most dramatic change in $T_{g w}$ profile (see Fig. 17) once fabrication was considered. As expected, sharp temperature increases in the bifurcation transition areas did occur. However, the area of 200 channels was extended well into the combustion chamber to place the bifurcation point beyond the critical heat transfer area and reduce the temperature peaks. This resulted in some over cooling of the chamber upstream of the throat.

Coolant channel pressure drops were calculated for each design. Each of the designs resulted in a higher coolant pressure drop than the baseline. These pressure drop increases ranged from 2 to 33 percent. Again, the highest coolant pressure drop came from design 2 . The lowest coolant pressure drop increase ( 2 percent), came from design 6, which used 100 stepped coolant channels. The coolant pressure drops were lower, once fabrication was considered, for designs 1,3 , and 6 , due to limiting the coolant channel height to $0.51 \mathrm{~cm}(0.20 \mathrm{in}$.) for fabrication.

Imposing fabrication constraints on the seven designs impacted the coolant channel geometries as well as the $\mathrm{T}_{\mathrm{gw}}$ and coolant pressure drops. However, it was still possible to meet the target $T_{g w}$ with an acceptable coolant pressure drop. The fabrication constraints greatly modified designs 1,3 , and 6 . This was due to the reduction in their highest aspect ratio from 40 down to the limit of 8 . This raised the maximum $T_{g w}$ for designs 1,3 , and 6 above the limit of $667 \mathrm{~K}\left(1200^{\circ} \mathrm{R}\right)$ (see Table III). However, lowering the aspect ratio of these designs greatly

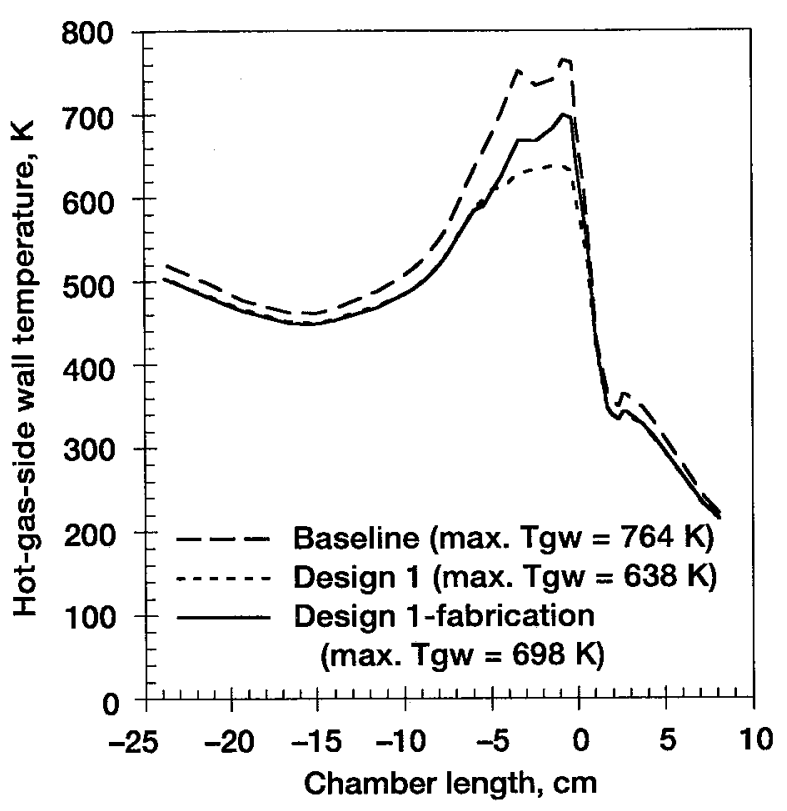

Figure 13.-Hot-gas-side wall temperature comparison of Design 1 and baseline, with and without consideration for fabrication.

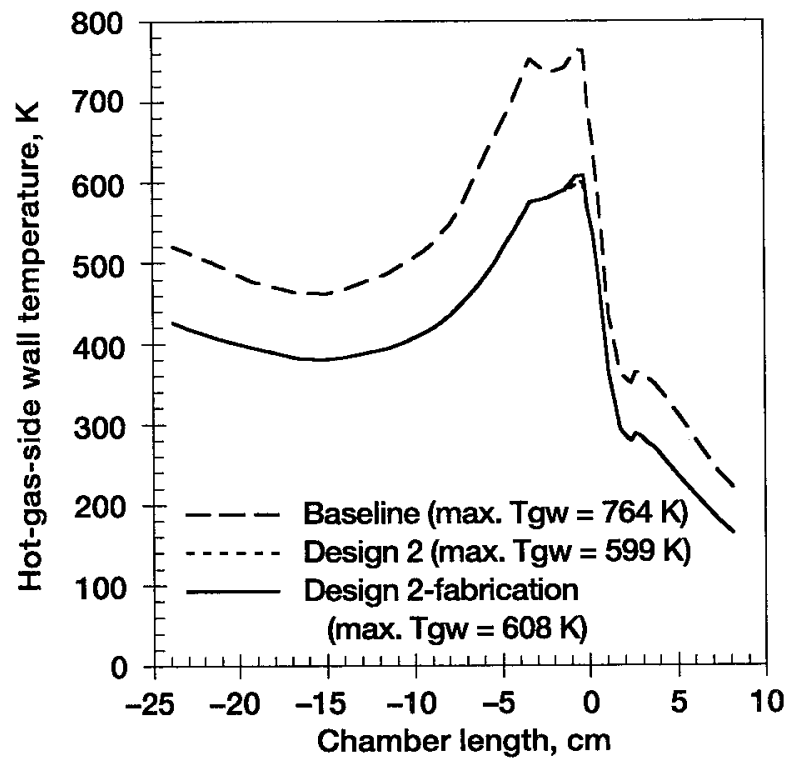

Figure 14.-Hot-gas-side wall temperature comparison of Design 2 and baseline, with and without consideration for fabrication. 


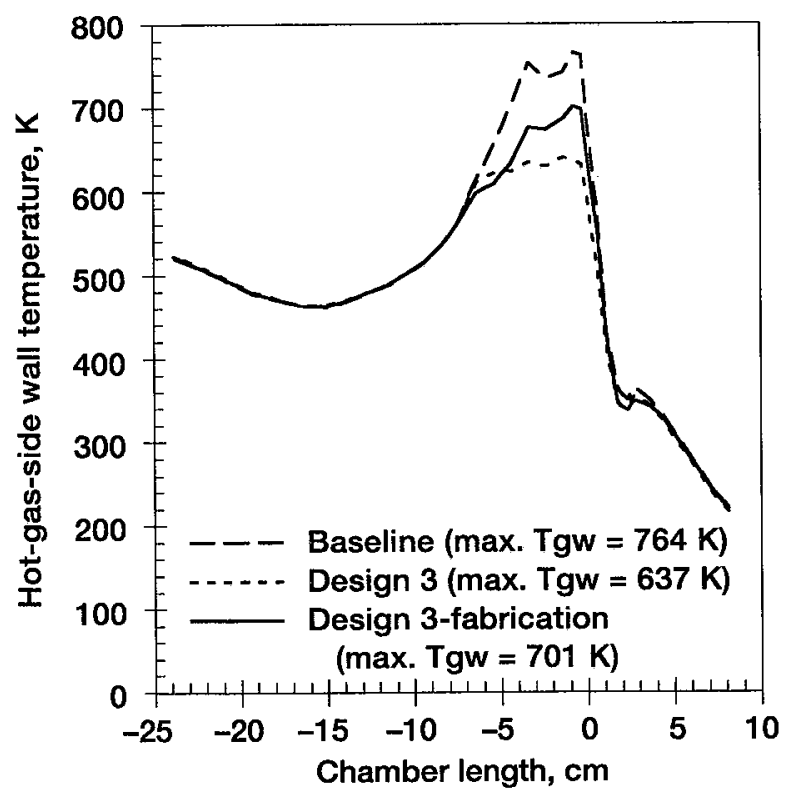

Figure 15.-Hot-gas-side wall temperature comparison of Design 3 and baseline, with and without consideration for fabrication.

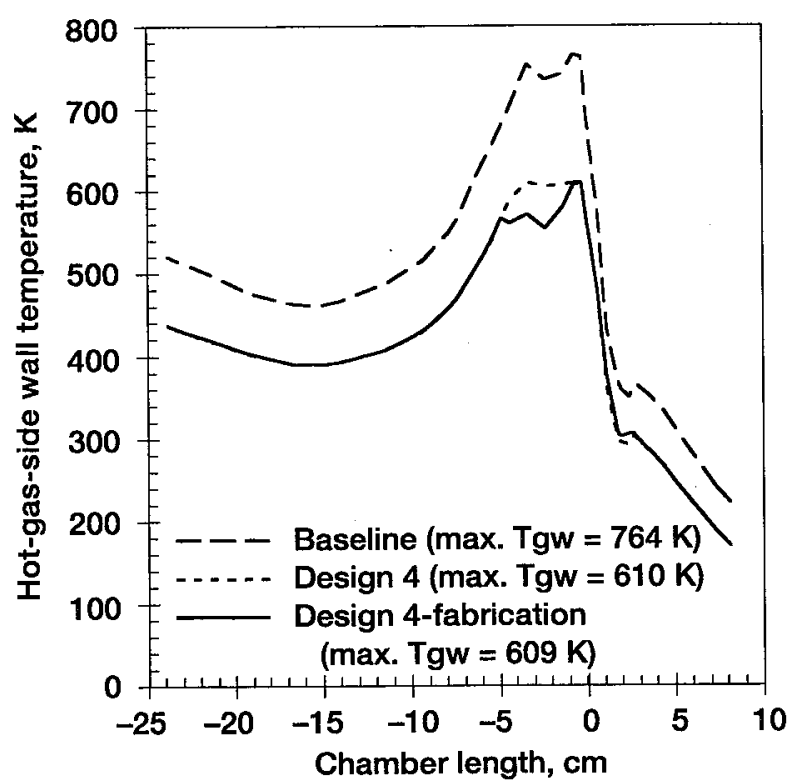

Figure 16.-Hot-gas-side wall temperature comparison of Design 4 and baseline, with and without consideration for fabrication.

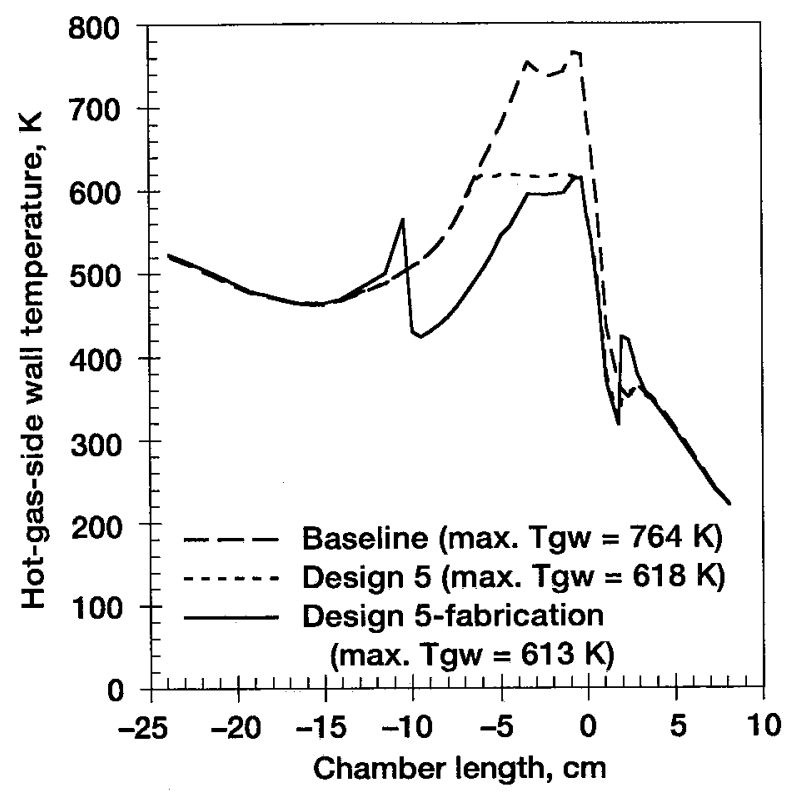

Figure 17. - Hot-gas-side wall temperature comparison of Design 5 and baseline, with and without consideration for fabrication.

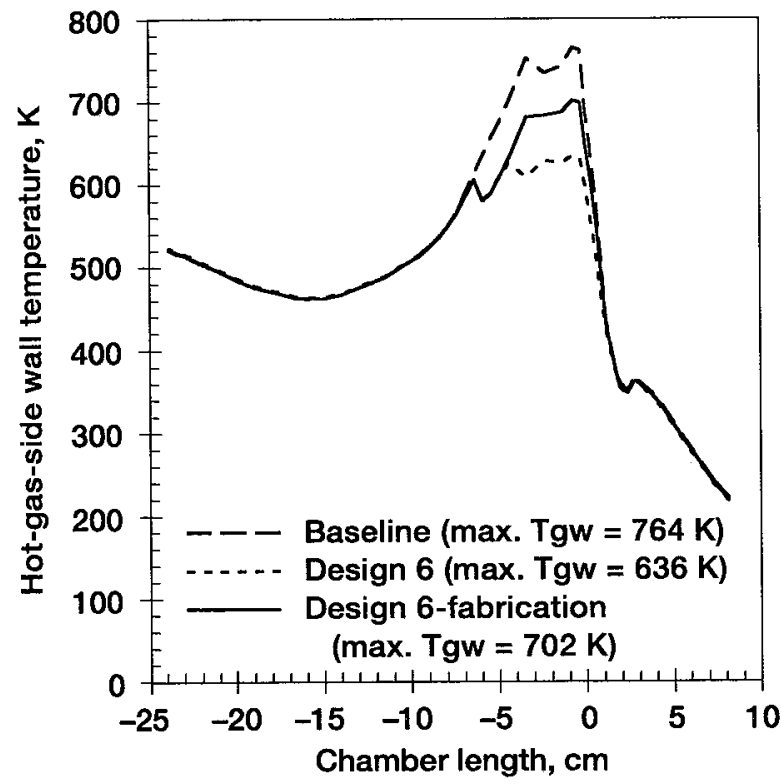

Figure 18.-Hot-gas-side wall temperature comparison of Design 6 and baseline, with and without consideration for fabrication. 


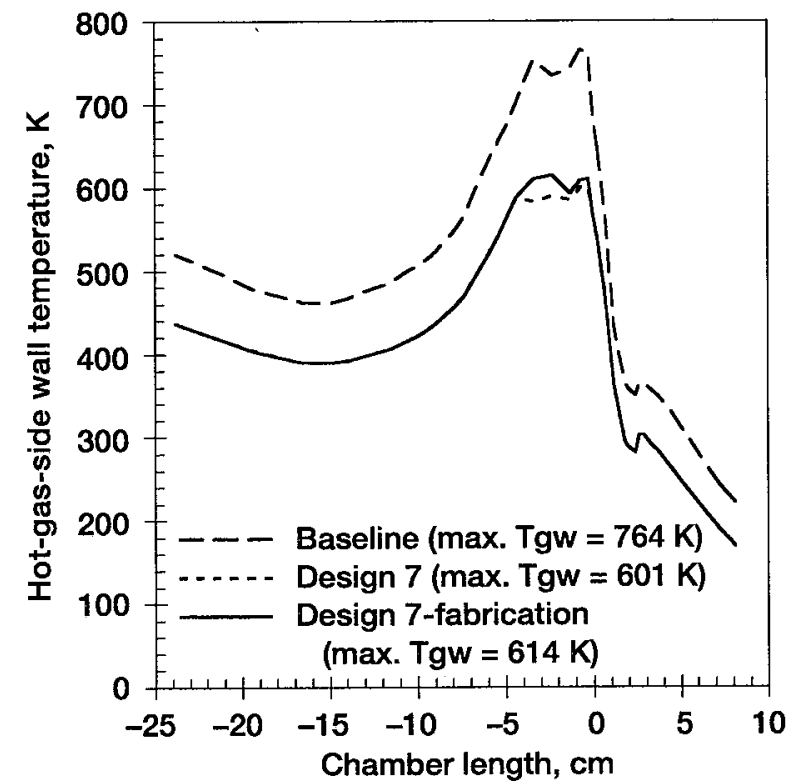

Figure 19.-Hot-gas-side wall temperature comparison of Design 7 and baseline, with and without consideration for fabrication.

reduced their coolant pressure drops. Designs 2,4 , and 7 did not have a significant change once fabrication was considered, since their geometries were close to the fabrication constraints initially (see Table II). The $\mathrm{T}_{\mathrm{gw}}$ profiles for designs 2, 4, and 7 did vary with consideration for fabrication, but did not go above the limit of $667 \mathrm{~K}$ $\left(1200^{\circ} \mathrm{R}\right)$. Likewise, the coolant pressure drops for these designs did not vary greatly. Design 5 did have significant geometry changes with consideration for fabrication, although it was already close to the fabrication limits. This was due to the inclusion of the transition area in the bifurcation regions and the need to eliminate the $T_{g w}$ spikesin these regions. Although design 5's geometry made a dramatic change, the maximum $\mathrm{T}_{\mathrm{gw}}$ was below the $667 \mathrm{~K}\left(1200^{\circ} \mathrm{R}\right)$ limit, and the coolant pressure drop remained about the same. The fabrication constraints imposed did limit some of the designs in meeting the $T_{\mathrm{gw}}$ target, however, a design was possible which was able to reduce the $\mathrm{T}_{\mathrm{gw}}$ below the $667 \mathrm{~K}\left(1200^{\circ} \mathrm{R}\right)$ limit without a severe coolant pressure drop penalty.

Once fabrication was taken into consideration, the seven designs were compared again. As in the case without consideration for fabrication, the use of HARCC throughout the entire chamber length, designs 1 and 2, produced similar $\mathbf{T}_{\mathrm{gw}}$ profiles to those that used HARCC only in the throat region. Designs 1 and 2 also continued to have higher pressure drop increases, 11 and 33 percent respectively. Therefore, using HARCC throughout the entire chamber length does not have significant advantage over using HARCC in the throat region, but does have a significant adverse impact on coolant pressure drop. The use of 200 channels throughout the entire chamber length, designs 2,4 , and 7 , again produced the highest benefit to the $\mathrm{T}_{\mathrm{gw}}$, after fabrication was considered, with reductions of 19.5 to 20 percent, but still incurred coolant pressure drop increases of 24 to 33 percent. This shows that using 200 channels for the entire chamber length could significantly benefit the $\mathrm{T}_{\mathrm{gw}}$ profile, but would have a high coolant pressure drop penalty. All of the HARCC designs, once fabrication was accounted for, produced reductions in $\mathrm{T}_{\mathrm{gw}}$ of at least 8 percent, with as little as a 2 percent increase in coolant pressure drop (design 6, in Table II). This shows that the use of HARCC benefits the $T_{g w}$ independent of channel shape. Based upon the $\mathrm{T}_{\mathrm{gw}}$ profile and coolant pressure drop, design 5 was again the design which would result in the highest overall benefit. It had a 20 percent reduction in $\mathrm{T}_{\mathrm{gw}}$ and a 9 percent increase in coolant pressure drop.

Bifurcated coolant channels have always been used for the experimental investigations of HARCC at NASA Lewis Research Center. This was based on the enhanced fin effect of having multiple, thin fins in the bifurcated region to enhance cooling. It was assumed that the coolant pressure drop took a penalty for the increased number of channels, but that the enhanced cooling outweighed the penalty. This study shows that the use of bifurcated high aspect ratio coolant channels does enhance the cooling due to the increased number of coolant channels in the bifurcated region, but does not greatly increase the coolant pressure drop over a chamber which does not bifurcate the channels. Bifurcating channels does pose some manufacturing issues, such as the transition areas. These result in the temperature spikes and some over cooling, as seen in Fig. 17. However, if a coolant channel design was attempted without constraining the total coolant flow area to match a baseline, these issues could be minimized and the benefits of HARCC and bifurcated channels still obtained. Therefore, use of bifurcated coolant channels is recommended if a reduction in $\mathrm{T}_{\mathrm{gw}}$ is desired, and a minimal increase in coolant pressure drop can be tolerated.

\section{Concluding Remarks}

The effect of high aspect ratio (height/width) cooling channels (HARCC) on hot-gas-side wall temperature $\left(\mathrm{T}_{\mathrm{gw}}\right)$ and coolant pressure drop was analytically investigated, considering length of the HARCC, number of coolant channels, and coolant channel shape. The RTE and TDK codes were coupled to determine the $\mathrm{T}_{\mathrm{gw}}$ and coolant pressure drop. First, the HARCC designs were determined without consideration for fabrication and produced 
$\mathrm{T}_{\mathrm{gw}}$ reductions of 16.5 to 22 percent from the given baseline, with 7.5 to 33 percent increases in coolant pressure drop. The HARCC designs were then modified to reflect current milling fabrication techniques and limitations. The designs produced $\mathrm{T}_{\mathrm{gw}}$ reductions of 8 to 20 percent from the given baseline, with 2 to 33 percent increases in coolant pressure drop. The fabrication constraints imposed did limit some of the designs in meeting the $\mathrm{T}_{\mathrm{gw}}$ target, however, a design was possible which was able to reduce the $\mathrm{T}_{\mathrm{gw}}$ below the $667 \mathrm{~K}\left(1200^{\circ} \mathrm{R}\right)$ limit without a severe coolant pressure drop penalty. Using HARCC for the entire chamber length was shown to have no significant $\mathrm{T}_{\mathrm{gw}}$ advantage over using HARCC only in the throat region, but did significantly increase the coolant pressure drop. Using 200 coolant channels for the entire chamber length was shown to benefit the $T_{\text {gw }}$ profile, but would have a high coolant pressure drop penalty. All of the HARCC designs, once fabrication was considered, produced reductions in $\mathrm{T}_{\mathrm{gw}}$ of at least 8 percent, with as little as a 2 percent increase in coolant pressure drop. Therefore, the use of HARCC was shown to have an overall benefit, independent of coolant channel shape. The HARCC design which used bifurcated coolant channels had the most overall benefit with $\mathrm{T}_{\mathrm{gw}}$ (20 percent reduction) and coolant pressure drop ( 9 percent increase). This study showed that using bifurcated high aspect ratio channels gave enhanced cooling in the throat region due to the use of multiple coolant channels, but did not greatly increase the coolant pressure drop over a chamber which did not bifurcate the channels.

\section{$\underline{\text { References }}$}

1. Carlile, J.A., Quentmeyer, R.J.: An Experimental Investigation of High-Aspect-Ratio Cooling Passages, $28^{\text {th }}$ Joint Propulsion Conference, 1992, AIAA 92-3154 (Also NASA TM-105679).

2. Wadel, M.F., Meyer, M.L.: Validation of High Aspect Ratio Cooling in a $89 \mathrm{kN}$ (20000 lbf) Thrust Combustion Chamber, $32^{\text {nd }}$ Joint Propulsion Conference, 1996, AIAA 96-2584 (Also NASA TM-107270).

3. Wadel,M.F., Quentmeyer, R.J., Meyer, M.L.: A Rocket Engine Design for Validating the High Aspect Ratio Cooling Channel Concept, NASA CP-3282, Vol. II, pp. 145-150.

4. Muss, J.A., Nguyen, T.V., Johnson, C.W.: User's Manual for Rocket Combustor Interactive Design (ROCCID) and Analysis Computer Program, NASA CR-187109, Contract NAS3-25556, May 1991.

5. Naraghi, M.H.N.: User's Manual, RTE-A Computer Code for Three-Dimensional Rocket Thermal Evaluation, Manhattan College, Riverdale, NY September 1993, under NASA grant NAG 3-892.

6. Nickerson, G.R., Coats, D.E., Dang, A.L., Dunn, S.S., Kehtarnavaz, H.: Two-Dimensional Kinetics(TDK) Nozzle Performance Computer Program, NAS8-36863, March 1989.

7. Quentmeyer, R.J.: Experimental Fatigue Life Investigation of Cylindrical Thrust Chambers, $13^{\text {th }}$ Propulsion Conference, 1977, NASA TMX-73665. 


\begin{tabular}{|c|c|c|c|c|}
\hline \multicolumn{3}{|c|}{ REPORT DOCUMENTATION PAGE } & \multicolumn{2}{|r|}{$\begin{array}{l}\text { Form Approved } \\
\text { OMB No. 0704-0188 }\end{array}$} \\
\hline \multicolumn{5}{|c|}{ 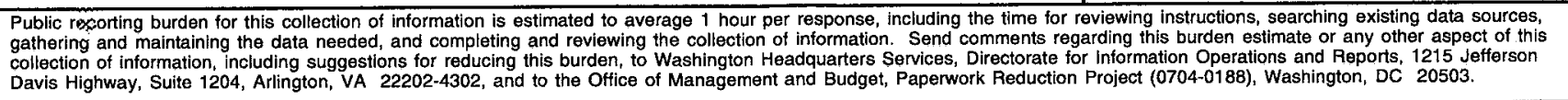 } \\
\hline 1. AGENCY USE ONLY (Leave blank) & \begin{tabular}{c|c} 
2. REPORT DATE \\
June 1997
\end{tabular} & \multicolumn{3}{|c|}{$\begin{array}{l}\text { 3. REPORT TYPE AND DATES COVERED } \\
\text { Technical Memorandum }\end{array}$} \\
\hline \multicolumn{3}{|c|}{$\begin{array}{l}\text { 4. TITLE AND SUBTITLE } \\
\text { Comparison of High Aspect Ratio Cooling Channel Designs for a Rocket } \\
\text { Combustion Chamber }\end{array}$} & \multirow{2}{*}{\multicolumn{2}{|c|}{$\begin{array}{l}\text { 5. FUNDING NUMBERS } \\
\text { WU-242-20-06-00 }\end{array}$}} \\
\hline \multicolumn{3}{|l|}{$\begin{array}{l}\text { 6. AUTHOR(S) } \\
\text { Mary F. Wadel }\end{array}$} & & \\
\hline \multicolumn{3}{|c|}{$\begin{array}{l}\text { 7. PERFORMING ORGANIZATION NAME(S) AND ADDRESS(ES) } \\
\text { National Aeronautics and Space Administration } \\
\text { Lewis Research Center } \\
\text { Cleveland, Ohio } 44135-3191\end{array}$} & \multicolumn{2}{|c|}{$\begin{array}{l}\text { 8. PERFORMING ORGANIZATION } \\
\text { REPORT NUMBER }\end{array}$} \\
\hline \multicolumn{3}{|c|}{ 9. SPONSORING/MONITORING AGENCY NAME(S) AND ADDRESS(ES) } & \multicolumn{2}{|c|}{$\begin{array}{l}\text { 10. SPONSORING/MONITORING } \\
\text { AGENCY REPORT NUMBER } \\
\text { NASA TM-107473 } \\
\text { AIAA-97-2913 }\end{array}$} \\
\hline \multicolumn{5}{|c|}{$\begin{array}{l}\text { 11. SUPPLEMENTARY NOTES } \\
\text { Prepared for the 33rd Joint Propulsion Conference and Exhibit cosponsored by AIAA, ASME, SAE, and ASEE, Seattle, } \\
\text { Washington, July 6-9,1997. Responsible person, Mary F. Wadel, organization code 5830, (216) 433-7510. }\end{array}$} \\
\hline \multirow{2}{*}{\multicolumn{3}{|c|}{$\begin{array}{l}\text { 12a. DISTRIBUTION/AVAILABILITY STATEMENT } \\
\text { Unclassified - Unlimited } \\
\text { Subject Categories } 20 \text { and } 34 \\
\text { This publication is available from the NASA Center for AeroSpace Information, (301) 621-0390. }\end{array}$}} & \multirow{2}{*}{\multicolumn{2}{|c|}{ 12b. DISTRIBUTION CODE }} \\
\hline & & & & \\
\hline \multicolumn{5}{|c|}{$\begin{array}{l}\text { An analytical investigation on the effect of high aspect ratio (height/width) cooling channels, considering different } \\
\text { coolant channel designs, on hot-gas-side wall temperature and coolant pressure drop for a liquid hydrogen cooled rocket } \\
\text { combustion chamber, was performed. Coolant channel design elements considered were; length of combustion chamber } \\
\text { in which high aspect ratio cooling was applied, number of coolant channels, and coolant channel shape. Seven coolant } \\
\text { channel designs were investigated using a coupling of the Rocket Thermal Evaluation code and the Two-Dimensional } \\
\text { Kinetics code. Initially, each coolant channel design was developed, without consideration for fabrication, to reduce the } \\
\text { hot-gas-side wall temperature from a given conventional cooling channel baseline. These designs produced hot-gas-side } \\
\text { wall temperature reductions up to } 22 \text { percent, with coolant pressure drop increases as low as } 7.5 \text { percent from the } \\
\text { baseline. Fabrication constraints for milled channels were applied to the seven designs. These produced hot-gas-side } \\
\text { wall temperature reductions of up to } 20 \text { percent, with coolant pressure drop increases as low as } 2 \text { percent. Using high } \\
\text { aspect ratio cooling channels for the entire length of the combustion chamber had no additional benefit on hot-gas-side } \\
\text { wall temperature over using high aspect ratio cooling channels only in the throat region, but increased coolant pressure } \\
\text { drop } 33 \text { percent. Independent of coolant channel shape, high aspect ratio cooling was able to reduce the hot-gas-side } \\
\text { wall temperature by at least } 8 \text { percent, with as low as a } 2 \text { percent increase in coolant pressure drop. The design with the } \\
\text { highest overall benefit to hot-gas-side wall temperature and minimal coolant pressure drop cooling can now be done in } \\
\text { relatively short periods of time with multiple iterations. }\end{array}$} \\
\hline \multirow{2}{*}{\multicolumn{3}{|c|}{$\begin{array}{l}\text { 14. SUBJECT TERMS } \\
\text { Rocket combustors; Rocket engine; Aspect ratio; Chamber liner }\end{array}$}} & & $\begin{array}{l}\text { 15. NUMBER OF PAGES } \\
14\end{array}$ \\
\hline & & & & $\begin{array}{l}\text { 16. PRICE CODE } \\
\text { A03 }\end{array}$ \\
\hline $\begin{array}{l}\text { 17. SECURITY CLASSIFICATION } \\
\text { OF REPORT } \\
\text { Unclassified }\end{array}$ & $\begin{array}{l}\text { 18. SECURITY CLASSIFICATION } \\
\text { OF THIS PAGE }\end{array}$ & $\begin{array}{l}\text { 19. SECURITY CLASSIFICA } \\
\text { OF ABSTRACT }\end{array}$ & & 20. LIMITATION OF ABSTRACT \\
\hline Unclassified & Unclassified & Unclassified & & \\
\hline NSN 7540-01-280-5500 & & & & $\begin{array}{l}\text { andard Form } 298 \text { (Rev. 2-89) } \\
\text { sscribed by ANSI Std. Z39-18 } \\
8-102\end{array}$ \\
\hline
\end{tabular}

